\section{Pyrrolic Acids in Porphyrin Oxidation}

Acros such as 4-methyl-2,3,5-pyrroletricarboxylic (I), 4 - methyl - 3 - ethyl - 2,5 - pyrroledicarboxylic (II), 4 - methyl - 3 - propionic - 2,5 - pyrroledicarboxylic (III), and 4-ethyl-2,3,5-pyrroletricarboxylic (IV) are found among the oxidation products of some naturally occurring porphyrins and dihydroporphyrins.

A solution or suspension of the porphyrin in $2 \mathrm{~N}$ potassium carbonate was treated at room temperature with sufficient saturated solution of potassium permanganate to allow the oxidant still to be present after ten minutes. The excess of the permanganate was destroyed with sodium sulphite. After filtering off the manganese dioxide, the solution was cooled to $10^{\circ} \mathrm{C}$, acidified with concentrated hydrochloric acid (congo red as indicator), filtered again if necessary and finally freed from oxalic acid with calcium chloride at $p \mathrm{H} \mathrm{4 \cdot 5-5}$. Then the clear solution, thus obtained, was made strongly acid with concentrated hydrochloric acid. This solution was extracted four times with peroxide-free ether, and after evaporation to dryness the residue was treated with a small amount of distilled water and filtered. The filtrate was submitted to chromatographic analysis on Whatman No. 1 paper and compared with samples of synthetic pyrrolic acids. The solvents used were: $n$-butyl alcohol/acetic acid/water (4:1:5); ethyl alcohol / 33 per cent ammonia/ water (2v:1:4); $n$-butyl alcohol / $2 N$ ammonia $(1: 1)$. The pyrrolic acids were easily detected by spraying the paper first with diazotized sulphanilic acid and then with a dilute sodium hydroxide solution. The amount of porphyrin required is $5-20 \mathrm{mgm}$.

Table 1 shows the compounds oxidized and the acids obtained.

\begin{tabular}{|c|c|c|c|c|}
\hline Compounds oxidized & I & $\begin{array}{c}\text { Acid } \\
\text { II }\end{array}$ & $\begin{array}{l}\text { ained } \\
\text { III }\end{array}$ & IV \\
\hline $\begin{array}{l}\text { Protoporphyrin IX } \\
\text { Hæmin } \\
\text { Mesoporphyrin IX } \\
\text { Pliæophorbide } a \\
\text { Mesophæophorbide } a \\
\text { Phæoporphyrin } a_{b} \\
\text { Phæophorbide } b \\
\text { Phæophytin } a+b\end{array}$ & $\begin{array}{l}+ \\
+ \\
+ \\
+ \\
+ \\
+\end{array}$ & $\begin{array}{l}+ \\
+ \\
+ \\
+ \\
+\end{array}$ & $\begin{array}{l}+ \\
+ \\
+ \\
+ \\
+ \\
+ \\
+ \\
(+)\end{array}$ & $\stackrel{+}{+}$ \\
\hline
\end{tabular}

With the exception of the vinyl and formyl groups oxidized to carboxyl groups, the other side-chains are found to be unchanged, and this provides us with a useful method for investigating the nature of the substitution groups 1 to 8 ( $\mathrm{H}$. Fischer system of nomenclature) of a porphyrin.

The occurronce of these acids is, moreover, a chomical indication that the porphyrin systom must be considered a resonance hybrid of tautomeric forms.

Acid (III) cannot be detected after the oxidation of phæophytin $a+b$, until after the degradation mixture has been hydrolysed. This means that acid (III), after tho oxidation process, is still linkod to the phytilic residue. This is therefore a clear proof of the phytol position in chlorophyll $a$ and in chlorophyll $b$.

The presence of acid (III) in the oxidation products of pheophorbide $a$ and mosophxophorbide $a$ is difficult to understand becauso the ring from which our acid (III) is formed has a pyrrolinie structure and is, according to $H$. Fischer, very difficult to dehydro genate by oxidative degradation. Furthermore, from a quantitative point of viow, it seems that, starting from mesophæophorbide $a$ and phæoporphyrin $a$, comparable yields of acid (III) are obtained.
These results have prompted us to undertake investigations on dihydroporphyrins to establish the position of the two hydrogen atoms. A full account of the present work will appear in the Annali $d i$ Chimica.

Rodolfo A. Nicolaus

Lorenzo MaNGoni

Luctano Caglioti

Istituto di Chimica Organica dell'Università, Rome. July 13.

\section{Structure of Anhydronium Bases}

I) URING recent years, a number of authors ${ }^{1-5}$ have attributed to several alkaloids containing the $\beta$-carboline system,<smiles>c1ccc2c(c1)[nH]c1cnccc12</smiles>

the structure of anhydronium bases; for example, Schwarz ${ }^{4}$ suggests :

(I)<smiles>Cn1cc2nc3c4cccc3c3c(c1)c(cn3C)-c2n4</smiles>

following the formulation first introduced by Armit and Robinson ${ }^{6}$ in 1925, who described an analogous derivative of the $\alpha$-carboline.

However, it appears to us unnecessary to write a formula bearing separated charges, because the covalent formula might rightly account for the chemical and physical properties of the anhydronium bases, provided due attention is given to the valence state of the nitrogen atoms in these molecules.

The main characters of anhydronium bases appear to be : (i) a pyridine-like nitrogen on ring $B$ (formula I), that is, a nitrogen in the valence state $s^{2} x y z, V_{8}$ (or, as reported in some examples given by Armit and Robinson ${ }^{8}$, a carbon atom in its trigonal state); (ii) an amino-like nitrogen on ring $C$, that is, a nitrogen in the valence state $s x^{2} y z, V_{3}$. It follows that the anhydronium bases are characterized by two hetero-aromatic condensed rings, one with five and the other with seven conjugated $\pi$-electrons, built up with the contribution of the nitrogen $p$ and lone pair electrons respectively, constituting a system clearly related to azulene.

The passage from the carbolines to the corresponding anhydronium bases recalls in fact that from naphthalene to azulene. Tho main features of this change are the spectral bathochromic shift, the appearance of a dipole momont and a marked increase in the strength of the base. All the anhydronium bases are reported to be yellow to deeply red substances, whereas the corresponding carbolines are colourless ${ }^{3}$; they are very strong bases? ${ }^{7}$, their basicity depending on the mutual position of the two nitrogen atoms? Also, a dipole moment of about $8 \mathrm{D}$. has been reported for sempervirine ${ }^{2}$.

The best way of testing the above assumptions seemed to us to be to calculate the charge distribution, dipole moment and spectral shift for a simple molecule possessing only the fundamental conjugated system of the anhydronium bases, represented by rings $B$ and $C$. We chose, therefore, as a model the compounds (III) and (IV), the last of which possesses 